\title{
Exposure Planned Dose Units
}

National Cancer Institute

\section{Source}

National Cancer Institute. Exposure Planned Dose Units. NCI Thesaurus. Code C83036.

The units for the planned amount of exposure that a subject will receive. 